\title{
An Analysis of Constraints in Large Scale Dissemination of System of Rice Intensification (SRI) in Odisha, India
}

\author{
A. Pal, D.S. Dhakre and D. Bhattacharya* \\ Institute of Agriculture, Visva-Bharati, Santiniketan, West Bengal, India \\ *Corresponding author
}

\begin{tabular}{l} 
K e y w o r d s \\
SRI, Perceptions, \\
Constraints, \\
Adoption, \\
Expansion \\
\hline Article Info \\
$\begin{array}{l}\text { Accepted: } \\
15 \text { June } 2019 \\
\text { Available Online: } \\
\text { 10 July } 2019\end{array}$ \\
\hline
\end{tabular}

\section{A B S T R A C T}

Rice is the staple food of Odisha in terms of area, production and yield. System of Rice Intensification (SRI) involves adoption of changes in management practices of rice cultivation creating a favourable condition for crop growth with less utilization of inputs. Despite the benefits, SRI has not adopted by the farmers as expected in the state. This paper attempted to analyse the perception of Odisha farmers regarding major constraints hindering widespread of SRI by different categories of farmers (i.e. adopters, dropouts and non-adopters) in the state and the positive impact of SRI. The study indicates that around $70 \%$ of farmers had positive outlook for SRI in terms of yield, profitability and improved soil status followed by reduced use of critical inputs. Maintaining required water at field situation, difficulty in mechanical weeding, lack of assured source of irrigation, covering higher area under mechanical weeder, erratic rainfall, lack of availability of skilled labour for practicing various methods of SRI particularly transplanting and weeding, non-availability of sufficient FYM and green manure and biofertilizers are the major constraints in widespread adoption of SRI as perceived by the farmers. SRI area expansion hindered mainly because of infeasible land topography, area saturation and lack of farmers' interest.

\section{Introduction}

In Asia, more than $80 \%$ of the people consume rice as their staple food and their primary food security is entirely depends on the volume of rice produced in this part of the world. India is second largest producer of rice after China and has an area of over $45.5 \mathrm{~m}$ ha (Thyagarajan and Gujja, 2013) and production of $105.31 \mathrm{mt}$ with yield of $2393 \mathrm{~kg} / \mathrm{ha}$ (Anonymous, 2013a). For production of $1 \mathrm{~kg}$ rice, 3000-5000 litre of irrigation water is required. For more than 60 per cent of the world people rice is an important staple food crop. Rice compensates about 31 percent of total calorie intake in India (Gathorne-Hardy at al., 2016). The normal annual rainfall in Odisha is around $1451.2 \mathrm{~mm}$, which is very erratic. Again, the cultivable land is reducing due to growing demand for industrialization \& housing. So, Odisha is facing rising stress on land and water resources, enhancing rice yield 
is crucial for recovering food security and alleviating poverty among masses in rural India. Rice covers around $46 \%$ of the GCA and is the major crop, covering around $62 \%$ of the total area under food grains in the state. Being the staple food the state economy is directly linked with improvements in production and productivity of rice. Odisha is the 5th largest rice-producing state in India accounting for roughly $6 \%$ of the national rice output

With the adoption of appropriate crop production technology such as SRI (Das et al., 2012), it is possible to minimize the yield loss due to climatic aberrations to a great extent and ensure better livelihood (Das et al., 2014) comprises a set of individual rice management practices that can help small and marginal farmers to increase their rice yields significantly without depending on hybrid seeds, mineral fertilizers and pesticides.

Despite of the beneficial impact of SRI methodology on the rice yield and overall income, the adoption is patchy and scale advantage is not achieved in the state of Odisha. Hence, in current paper, an attempt was made to assess the factors constrain the adoption of SRI.

\section{Materials and Methods}

A detailed survey was conducted involving 520 farm families from 11 districts of Odisha through questionnaires, structured interviews and were analysed with the objective of examining the benefits from SRI along with constraints perceived by farmers in adoption of SRI methodology. The respondents were categorized into three groups based on their land holding pattern as farmers having operational holding < 1 ha: Marginal farmers; 1-2 ha: small farmers and 2-5 ha: medium is as under during 2016 (From: Ministry of Agriculture and Farmers Welfare). Marginal farmers constituted $52.2 \%$ of the total farming households and the percentage varied from $52.1 \%$ in case of drop outs to $63.64 \%$ for nonadopters (Table 1). There are no large farmers in the study area based upon the land holding pattern.

The constraints are classified under different dimensions such as technological, transplanting, intercultural operations, infrastructure support, technical, social and economic. Large number of constraints faced by the farmers in adoption of SRI at farmers' field which vary across adopters, drop outs and non-adopters.

Constraints perceived by the farmers have been ranked for different categories of farmers by using Garrett' ranking technique. A 10 point scale was prepared according to their responses regarding their constraints which range from Scale: Lowest priority $=1$ and highest priority $=10$. Garrett's ranking technique is in the following manner:

Percentage position $=\frac{\left(R_{i j}-0.50\right)}{N_{j}} \times 100$

Where, $\mathrm{R}_{\mathrm{ij}}=$ Rank given for the $\mathrm{i}^{\text {th }}$ item by the $\mathrm{j}^{\text {th }}$ individual and

$\mathrm{N}_{\mathrm{j}}=$ Number of items ranked by the $\mathrm{j}^{\text {th }}$ individual

The percentage position of each rank was converted into scores using Garrett table (Garrett and Woodworth, 1969). For each constraint, scores of individual respondents were added together and were divided by total numbers of respondents and mean score for each constraint was ranked by arranging them in the descending order. The constraints faced by different group of farmers are different. The problem in area expansion under SRI and the farmers' perception for widespread of SRI are presented graphically. 


\section{Results and Discussion}

As per table-2, reasons for adoption of SRI methodology is different based on less seed rate followed by higher yield and profit maximization motivates marginal farmers, higher rice yield followed by less seed rate and more profits obtained respectively motivated small farmers while higher grain yield, more profit \& system compatibility are the major source of motivation for medium farmers in chronological order. Overall higher productivity of rice utilizing less seed in SRI over conventional practice resulting in profit maximization motivates the farmers to adopt SRI methodology.

Table-3 reveals that Lack of cooperation among farmers is the major constraint by adoptors followed by lack of education and confidence respectively in adoption of SRI methodology while for dropouts, lack of cooperation is the major constraint followed by lack of confidence and low education level respectively. While low level of confidence is the major social constraint for non-adoptors, low confidence followed by low level of cooperation and low level of education respectively. Lack of proper support price is the major economic constraint observed by all categories of farmers. Whereas lack of credit support by line department for adoptors, drop outs while inadequate support by them for purchase of feasible low cost implements is the constraint faced by adoptors and dropouts followed by inadequate financial support for various input procurement and cultivation but non adoptors opined that inadequate financial assistant followed by lack of credit support for procuring farm implements are the economic constraints in adoption of SRI.

Undulating land pattern is the major climate related problem for adoptors and dropuouts followed by water related issues and uneven rainfall unlikely, uneven rainfall pattern is the climatic constraint among non-adoption of SRI followed by topological issues and hydrological issues.

For adoptors, non-availability of adequate quantity to green manures followed by nonavailability of FYM and bio-fertilizers are the input constraints but there is no significant difference between inadequacy of green manure \& inadequacy of FYM. For dropouts, non-availability of green manures followed by non-availability of bio fertilizers and nonavailability of adequate FYM are the issues in adoption of the SRI methodology whereas, for non-adoptors, lack of bio-fertilizers followed by non-availability of green manure and insufficient FYM are the major constraints in SRI adoption.

Enhancement of knowledge and skill competency of farmers is important for adoption of any new technology. So, not solving technological problems is the major constraint for adoptors followed by inadequate training and guidance respectively.

For dropouts, sufficient guidance and programme review is required followed by availability of solution to the technological issues and adequate training \& exposures respectively. For capacity building of nonadoptors, adequate training-exposure is required followed by sufficient programme review by the implementer and funding agencies and solution to technological issues by the promoting agencies.

Availing improper hand holding support followed by complexity of SRI technology and unsuitability of SRI technology for a particular situation are the major constraints in adoption of SRI by the adoptors. For drop outs and non-adoptors, complexity of technology followed by unsuitability of a particular situation and improper technical support are the constraints in adoption of SRI. 

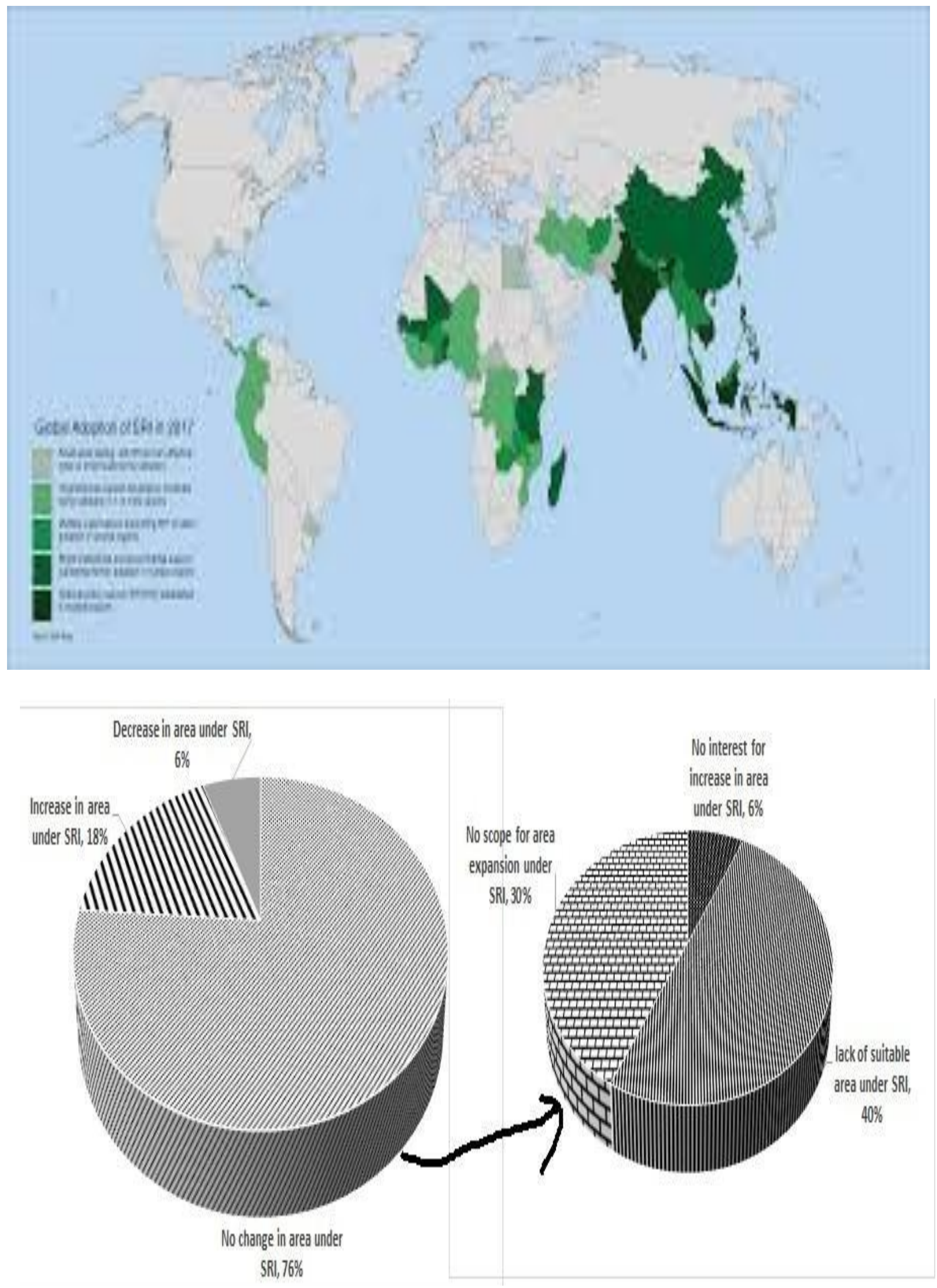


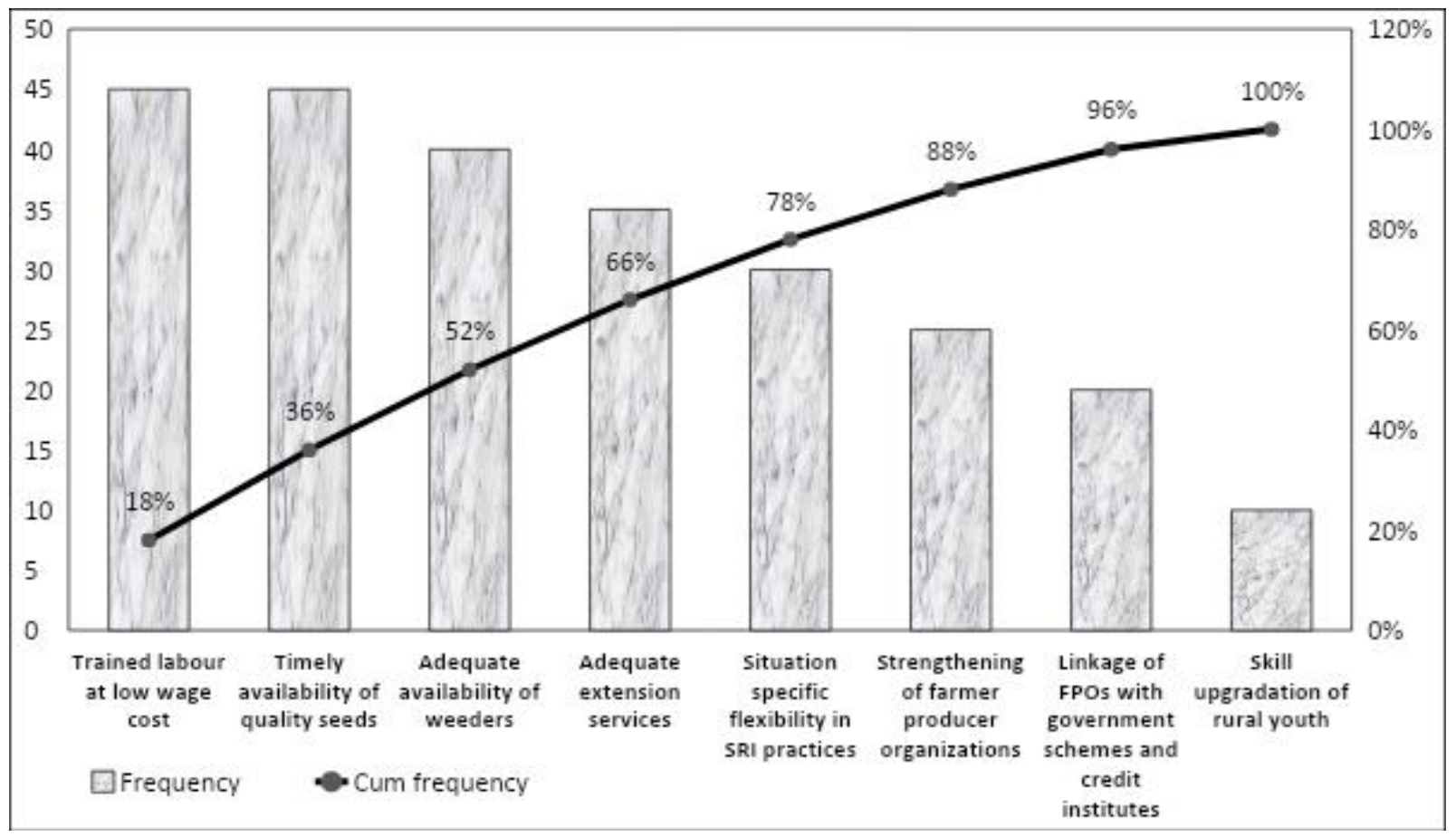

Table.1 Distribution of farmers according to farm size

\begin{tabular}{|l|c|c|c|c|}
\hline Farm types & Adopters & Drop outs / dis-adoptors & Non-adopters & Total \\
\hline Marginal & $155(52)$ & $76(52$ & $49(64)$ & $280(54)$ \\
\hline Small & $102(34)$ & $60(41)$ & $27(35)$ & $191(37)$ \\
\hline Medium & $40(14)$ & $10(7)$ & $1(1)$ & $49(9)$ \\
\hline Total & $297(100)$ & $146(100)$ & $77(100)$ & $520(100)$ \\
\hline
\end{tabular}

Table.2 Positive impact of SRI adoption as perceived by different categories of adoptors

\begin{tabular}{|c|c|c|c|c|c|c|c|c|}
\hline \multirow[t]{2}{*}{ Particulars } & \multicolumn{2}{|c|}{$\begin{array}{l}\text { Marginal } \\
\text { farmers }\end{array}$} & \multicolumn{2}{|c|}{ Small farmers } & \multicolumn{2}{|c|}{ Medium farmers } & \multicolumn{2}{|c|}{ overall } \\
\hline & $\begin{array}{c}\text { Garrett } \\
\text { Score }\end{array}$ & Rank & $\begin{array}{c}\text { Garrett } \\
\text { Score }\end{array}$ & Rank & $\begin{array}{l}\text { Garrett } \\
\text { Score }\end{array}$ & Rank & $\begin{array}{c}\text { Grrrett } \\
\text { Score }\end{array}$ & Rank \\
\hline Less seed rate & 70.48 & 1 & 68 & 2 & 67.8 & 2 & 67.56 & 2 \\
\hline Govt. subsidy on inputs & 42.58 & 4 & 42.86 & 4 & 36.14 & 6 & 40.50 & 5 \\
\hline Technically feasible & 41.22 & 5 & 41.87 & 5 & 41.76 & 5 & 40.48 & 6 \\
\hline $\begin{array}{l}\text { Increased water use } \\
\text { efficiency }\end{array}$ & 28.53 & 8 & 27.75 & 8 & 25.11 & 8 & 27.54 & 8 \\
\hline Compatible to the system & 29.1 & 7 & 28.53 & 7 & 61.56 & 3 & 42.10 & 4 \\
\hline Higher productivity & 67.95 & 2 & 68.85 & 1 & 68.49 & 1 & 69.23 & 1 \\
\hline More profitable & 54.21 & 3 & 54.36 & 3 & 54.19 & 4 & 55.24 & 3 \\
\hline Improve soil health & 31.19 & 6 & 30.42 & 6 & 27.31 & 7 & 30.12 & 7 \\
\hline
\end{tabular}


Table.3 Constraints in adoption of SRI methodology by different categories of farmers

\begin{tabular}{|c|c|c|c|c|c|c|c|}
\hline \multicolumn{2}{|r|}{ Constraints } & \multicolumn{2}{|c|}{ Adoptors } & \multicolumn{2}{|c|}{ Dropouts } & \multicolumn{2}{|c|}{ Non-adoptors } \\
\hline & & $\begin{array}{l}\text { Garrett } \\
\text { Score }\end{array}$ & Rank & $\begin{array}{l}\text { Garrett } \\
\text { Score }\end{array}$ & Rank & $\begin{array}{l}\text { Garrett } \\
\text { Score }\end{array}$ & Rank \\
\hline \multicolumn{8}{|c|}{ Social constraints } \\
\hline 1 & Lack of cooperation & 7.54 & 1 & 9.75 & 1 & 19.84 & 2 \\
\hline 2 & Lack of confidence & 2.97 & 3 & 8.36 & 2 & 52.42 & 1 \\
\hline 3 & Lack of education & 4.26 & 2 & 6.04 & 3 & 12.92 & 3 \\
\hline \multicolumn{8}{|c|}{ Economic constraints } \\
\hline 1 & No credit support for purchasing implements & 22.19 & 2 & 24.81 & 2 & 20.57 & 3 \\
\hline 2 & Inadequate financial support & 19.34 & 3 & 22.81 & 3 & 20.99 & 2 \\
\hline 5 & No support price & 27.32 & 1 & 35.56 & 1 & 25.11 & 1 \\
\hline \multicolumn{8}{|c|}{ Climatic constraints } \\
\hline 1 & Hydrological & 27.15 & 2 & 27.83 & 2 & 30.61 & 3 \\
\hline 2 & Topographical & 36.23 & 1 & 47.23 & 1 & 32.64 & 2 \\
\hline 3 & Erratic rainfall & 22.58 & 3 & 23.43 & 3 & 33.57 & 1 \\
\hline \multicolumn{8}{|c|}{ Input constraints } \\
\hline 1 & Non availability of sufficient FYM & 36.91 & 2 & 28.91 & 3 & 27.82 & 3 \\
\hline 2 & Non availability of Green manure & 37.01 & 1 & 40.07 & 1 & 28.34 & 2 \\
\hline 3 & Non availability of bio-fertilizer & 30.12 & 3 & 33.35 & 2 & 35.18 & 1 \\
\hline \multicolumn{8}{|c|}{ Constraint in Capacity building } \\
\hline 1 & Inadequate training and exposure & 22.01 & 2 & 29.73 & 3 & 60.93 & 1 \\
\hline 2 & Insufficient guidance and programme review & 19.18 & 3 & 37.53 & 1 & 49.43 & 3 \\
\hline 3 & No attempt to solve technological Problem & 25.33 & 1 & 34.23 & 2 & 40.53 & 2 \\
\hline \multirow{2}{*}{\multicolumn{2}{|c|}{ Constraints }} & \multicolumn{2}{|c|}{ Adoptors } & \multicolumn{2}{|c|}{ Dropouts } & \multicolumn{2}{|c|}{ Non-adoptors } \\
\hline & & $\begin{array}{c}\text { Garrett } \\
\text { Score }\end{array}$ & Rank & $\begin{array}{c}\text { Garrett } \\
\text { Score }\end{array}$ & Rank & $\begin{array}{c}\text { Garrett } \\
\text { Score }\end{array}$ & Rank \\
\hline \multicolumn{8}{|c|}{ Technological constraints } \\
\hline 1 & Complex technology & 9.77 & 2 & 24.87 & 1 & 61.49 & 1 \\
\hline 2 & Unsuitability of the technology & 7.07 & 3 & 15.12 & 2 & 38.26 & 2 \\
\hline 3 & Lack of hand holding support & 10.25 & 1 & 13.35 & 3 & 22.61 & 3 \\
\hline \multicolumn{8}{|c|}{ Constraint in Infrastructural support } \\
\hline 1 & $\begin{array}{l}\text { Difficulty in obtaining custom hiring services } \\
\text { at low cost }\end{array}$ & 9.08 & 3 & 13.6 & 3 & 17.84 & 3 \\
\hline 2 & $\begin{array}{c}\text { Non availability of adequate irrigation } \\
\text { infrastructure }\end{array}$ & 24.96 & 1 & 30.08 & 1 & 34.08 & 1 \\
\hline 3 & No credit support for purchasing implements & 18.97 & 2 & 15.57 & 2 & 19.72 & 2 \\
\hline \multicolumn{8}{|c|}{ Technical constraint } \\
\hline 1 & $\begin{array}{c}\text { Not possible to maintain water at field } \\
\text { situation }\end{array}$ & 60.36 & 1 & 60.32 & 1 & 41.29 & 1 \\
\hline 2 & Economic scarcity of labour & 59.64 & 2 & 59.64 & 2 & 52.92 & 2 \\
\hline 3 & $\begin{array}{c}\text { Not possible to weed more area with } \\
\text { mechanical weeder }\end{array}$ & 38.45 & 3 & 43.12 & 3 & 27.45 & 3 \\
\hline \multicolumn{8}{|c|}{ 9. Constraint in transplanting } \\
\hline 1 & Difficulty in maintaining ideal field & 63.7 & 1 & 62.63 & 1 & 41.03 & 2 \\
\hline 2 & $\begin{array}{l}\text { Lack of skill in nursery raising and } \\
\text { transplanting single tiny seedlings }\end{array}$ & 10.57 & 3 & 20.78 & 3 & 46.58 & 1 \\
\hline 3 & Labourer's reluctance & 36.44 & 2 & 37.77 & 2 & 27.22 & 3 \\
\hline
\end{tabular}


Irrigation management has greater role in enhancing productivity in SRI. For all types of the respondents, lack of facilities in adequately maintaining water level at field condition throughout the season, followed by economic scarcity of irrigation and nonavailability of custom hiring centres at low cost are the major factors of hindrance in adoption of SRI.

For all types of the respondents, lack of facilities in adequately maintaining water level at field condition throughout the season, followed by economic scarcity of labour and weeding more area with mechanical weeders are the major technical constraints in SRI adoption.

For adopters and dropouts, lack of facilities in adequately maintaining ideal field condition at transplanting time, followed by refusal of labourers for transplanting and difficulty in nursery raising and transplanting tiny seedlings. Non-adopters major constraint in adoption of SRI are lacking skill in nursery raising \& transplanting very small seedlings singly followed by maintaining proer water level $\mathrm{t}$ transplanting time. Mostly the farmers seldom utilize external labourers for transplanting in smaller areas for SRI, so difficulty associated with labourer reluctant (at $2^{\text {nd }}$ year onwards) is given lowest ranking by them.

\section{Area expansion under SRI}

Only 18 percent of the SRI practicing farmers had expressed their willingness on area expansion under SRI, 6 percentage of respondents said that they will not increase in area under SRI (Figure-1) whereas, 76 percent had expressed their inability to increase the area as 30 percent of them had already covered their entire rice area under SRI and for 40 percent, the remaining area under rice was not feasible for SRI. Among the farmers who opted for increasing area, main reasons were increase in yield and cost effectiveness of SRI over conventional practice. About six percent had expressed that they would decrease the area under SRI because of uncertainty in the production front due to drought and production was not commensurate with conventional practice and few had expressed that the SRI practices were too cumbersome and also labourers unwillingness to follow the practices particularly for transplanting and weeding operations.

Odisha has poor irrigation infrastructure and is continuously affected by adverse climatic condition. Average rice are in Odisha is 2.48 ac of which has only $35 \%$ is irrigated. Under such situation, SRI has positive impact on rice yield and household level income. So, some resource rich farmers should be selected for purchasing farm machineries and field level demonstrations on modified SRI methodology.

The study indicates that more than $70 \%$ of farmers had positive outlook for SRI in terms of yield, profitability and improved soil status, however, compatibility of the SRI to the existing farming system, technical feasibility, sustained production and increased water use efficiency were reported by only around 42 to 53 percent.

Future prospects of SRI method in the state

Figure-2 reveals that the majority of the respondents suggested that availability of trained and skilled labourers at affordable cost, timely availability of quality seeds, adequacy of mechanical weeders along with adequate extension services and situation specific flexibility in SRI practices will expand the scope of expansion of SRI in the state to a great extent (around 66\%). 
These are also intensified to enable all the respondents be benefitted from the practice. Seeking information about production \& marketing and innovativeness also had a positive impact on the adoption level. So, trainings, demonstrations and publications should be conducted regularly. Hence, interventions on these aspects need to be continued and strengthened to benefit all the farmers. Among the constraints expressed by the SRI beneficiaries, usage of weeders, nursery management and skill in square planting was found to be important.

\section{Suggestions}

Sufficient attempts required for motivating the farmers to adopt the SRI methodology by promoting cooperation among farmers, adequate handholding support by Government line Dept. \& NGOs, local exposure for developing confidence, assured irrigation facilities, custom hiring facilities for popularizing farm mechanization, redesigning location specific technology relating to different SRI components, providing adequate training to the young labourers, large scale promotion of farm machineries purchased by the able-farmers, conducting location specific trials, efforts to tap irrigation potential under the existing framework like suitability of diversion based irrigation systems \& water harvesting structures, insisting on applying soil test based recommended nutrition, developing more number of seed banks, involving women in all phases of programmes, preparing more community resource persons (CRPs) through communities, facilitating local exposures, intensifying trainings, conducting local trials, emphasizing institution building programmes, promoting SRI in cluster saturation basis in different crops, ensuring timely availing the critical inputs like seeds, timely operations, ensuring irrigation infrastructures development, observation of field days etc. should be followed to bring back the SRI drop outs and non adopters for SRI area expansion.

\section{Acknowledgement}

The authors are thankful to the funding agency, Tata Trusts and different NGOs working in Odisha for providing primary data for this study. Also the authors provide gratitude to Dept. of Agriculture, Govt. of Odisha for secondary data.

\section{References}

Anonymous (2013a). Annual Report (201213), Department of Agriculture and Cooperation, Marketing of Agriculture, Government of India, New Delhi. P.4.

Das A, Patel, D., Munda, G.C., Ramakrushna, G.I., Kumar, M. and Ngachang, S.V. 2014. Improving productivity, water and energy use efficiency in lowland rice (Oryza sativa) through appropriate establishment methods and nutrient management practices in the midaltitude of north-east India. Expl Agric 50(3):353-375.

Eleonora, Glogovetan Oana, Samochis, B., Dsnils, Loana Georgeta and Crisan, C. 2011. Criteria for the classification of the agricultural holdings. Agricultura Ştiinţă şi practică. P. 65-69.

Garrett, H.E. and Woodworth, R.S. 1969. Statistics in Psychology and Education. Bombay: Vakils, Feffer \& Simons Pvt. Ltd.

Gathorne-Hardy, A., D.N. Reddy, M. Venkatanarayana and B. Hariss-White (2016), 'System of Rice Intensification provides environmental and economic gains but at the expense of social sustainability: A multi-disciplinary analysis in India', Agricultural Systems, Vol. 143, pp. 159-168.

Narbaria, S., Sharma, L. S., Dhruv, Y. and Painkra, V.K. 2015. Science of System 
of rice intensification technology: an analysis of constraints perceived by the farmers in adoption of SRI technology. Plant Archives. 15(1): p. 159-162.

Singh, O.P., Rao, B.D., Singh, R., Bhattarai, M. 2015. Analysis of Constraints Influencing Sorghum Farmers Using Garrett's Ranking Technique; A Comparative Study of India and Nigeria. International Journal of Scientific Research and Management. 3(3): p. 2435-2440.
Oinam, T. and Sudhakar, B. 2014. Constraints faced by farmers in adoption of improved paddy practices in Bishnupriya district of Manipur state. 7(2): p 32-37.

Thiyagarajan, T.M. and B. Gujja. 2013. Transforming Rice Production with SRI (System of Rice Intensification) Knowledge and Practice. National Consortium on System of Rice Intensification, New Delhi. 200p.

\section{How to cite this article:}

Pal, A., D.S. Dhakre and Bhattacharya, D. 2019. An Analysis of Constraints in Large Scale Dissemination of System of Rice Intensification (SRI) in Odisha, India. Int.J.Curr.Microbiol.App.Sci. 8(07): 1898-1906. doi: https://doi.org/10.20546/ijcmas.2019.807.226 